\title{
Diagnostic Accuracy of PremaQuick versus Actim Partus in Prediction of Preterm Labor in Symptomatic Women within 14 Days
}

\author{
Mohannad Abu-Faza', Ibrahim A. Abdelazim ${ }^{1,2 *}$, Shikanova Svetlana ${ }^{3}$, Bassam Nusair ${ }^{4}$, \\ Rania H. Farag5, Sreelatha R. Nair ${ }^{1}$ \\ ${ }^{1}$ Department of Obstetrics and Gynecology, Ahmadi Hospital, Kuwait Oil Company, Ahmadi, Kuwait \\ ${ }^{2}$ Department of Obstetrics and Gynecology, Ain Shams University, Cairo, Egypt \\ ${ }^{3}$ Department of Obstetrics and Gynecology, Marat Ospanov, West Kazakhstan State Medical University (WKSMU), \\ Aktobe, Kazakhstan \\ ${ }^{4}$ Department of Obstetrics and Gynecology, Royal Medical Services, Amman, Jordan \\ ${ }^{5}$ Department of Obstetrics and Gynecology, Dar Al-Shafa Hospital, Hawalli, Kuwait \\ Email: ^dr.ibrahimanwar@gmail.com,Mabufaza@gmail.com, Shik.sv@mail.ru,bassam.nusair@hotmail.com, \\ drraniafarag1973@gmail.com, srnair@kockw.com
}

How to cite this paper: Abu-Faza, M., Abdelazim, I.A., Svetlana, S., Nusair, B., Farag, R.H. and Nair, S.R. (2018) Diagnostic Accuracy of PremaQuick versus Actim Partus in Prediction of Preterm Labor in Symptomatic Women within 14 Days. Open Journal of Obstetrics and Gynecology, 8, 741-755.

https://doi.org/10.4236/ojog.2018.88078

Received: July 1, 2018

Accepted: July 24, 2018

Published: July 27, 2018

Copyright $\odot 2018$ by authors and Scientific Research Publishing Inc. This work is licensed under the Creative Commons Attribution International License (CC BY 4.0).

http://creativecommons.org/licenses/by/4.0/

\section{Open Access}

\begin{abstract}
Background: Preterm labor (PTL) remains a major source of neonatal morbidity, and mortality. Currently the trans-vaginal cervical length (TVCL), and/or cervico-vaginal fetal fibronectin (fFN) are the common diagnostic tools used for prediction of PTL. Consequently, many women and their fetuses are exposed unnecessarily tocolysis and hospital admission. Objectives: This study was designed to compare the diagnostic accuracy of PremaQuick versus Actim Partus in prediction of PTL in symptomatic women within 14 days. Patients and Methods: Two-hundred and twenty women (220) were included in this comparative prospective study and classified into two groups: 110 women with threatened preterm labor (TPTL) in the study group, and 110 controls (no TPTL). Women included in the study were subjected to: through history, collection of the cervico-vaginal fluid (CVF) samples for assessment by PremaQuick and Actim Partus tests, followed by trans-vaginal cervical length (TVCL) assessment. Studied women managed according to the hospitals protocol, with follow-up weekly in the obstetrics outpatients' clinic after discharge from the hospital until delivery. The main outcome measures the diagnostic accuracy of PremaQuick versus Actim Partus in prediction of PTL in symptomatic women within 14 days of admission. Results: PremaQuick test was significantly more specific with higher positive predictive value (PPV) in prediction of PTL in symptomatic women within 14 days (95.5\% and $89.6 \%$; respectively) compared to $\mathrm{CL}<25 \mathrm{~mm}$ (56.3\% and $54.6 \%$;
\end{abstract}


respectively), ( $P=0.02$ and 0.03 ; respectively). In addition, PremaQuick test was significantly more sensitive with higher positive predictive value (PPV) in prediction of PTL in symptomatic women within 14 days $(39.8 \%$ and 89.6\%; respectively) compared to Actim Partus (13.9\% and 55.5\%; respectively), ( $P=0.001$ and 0.01 ; respectively). The Odds ratio and the relative risk for prediction of PTL in symptomatic women within 14 days were significantly high for PremaQuick compared to the $\mathrm{CL}<25 \mathrm{~mm}$, and Actim Partus. Conclusion: PremaQuick test seems to be the best complementary test to the $\mathrm{CL}<25$ in prediction of PTL in symptomatic women within 14 days. PremaQuick test compensates the low specificity and low PPV of the $\mathrm{CL}<25$ $\mathrm{mm}$ in prediction of PTL.

\section{Keywords}

PremaQuick, Actim Partus, Preterm Labor

\section{Introduction}

Preterm labor (PTL) before 37 weeks' gestation remains a major source of neonatal morbidity and mortality [1] [2]. PTL accounts for $60 \%$ of all perinatal deaths [3] [4]. PTL usually occurs after infection/inflammation, excessive myometrial mechanical stretch (multifetal gestation), fetal or maternal stress, and/or chorio-decidual hemorrhage [5] [6].

There are few reliable methods for detection of PTL and currently trans-vaginal cervical length (TVCL) and/or cervico-vaginal fetal fibronectin (fFN) are the common diagnostic tools used for prediction of PTL [7]. Both methods have high negative predictive values (NPVs), but relatively low positive predictive values (PPVs). Consequently, many women and their fetuses exposed to unnecessarily tocolysis, corticosteroid and hospital admission.

TVCL at $25 \mathrm{~mm}$ threshold has limited sensitivity (78.3\%) and specificity (71\%) in detection of PTL [8]. The cervico-vaginal fluid (CVF) is a complex mixture of secretions derived from the vagina, endo-cervix, decidua, amnion and chorion. Unlike the amniotic fluid, the CVF is easily accessible and its collection is minimally invasive. There are two cervico-vaginal biomarkers used for the prediction of PTL: fFN and phosphorylated insulin-like growth factor binding protein-1 (phIGFBP-1) [9]. fFN has poor PPV for detection of PTL and used mainly in detection of PTL due to its high NPV [10] [11]. fFN false results can obtained in cases of amniotic fluid contamination, vaginal bleeding, and unprotected sexual intercourse [4]. IGFBP-1 belongs to the insulin-like binding proteins super-family, released into CVF during the process of the chorio-decidual disruption, and its detection in the CVF associated with increased risk of PTL [12] [13]. Clinical diagnostic trials indicate that fFN and phIGFBP1 are good negative predictors of PTL (92\% specificity) with limited sensitivity, and PPVs in asymptomatic women [14]. 
Taylor et al., examined CVF for various inflammatory makers, and concluded that interlukein-6 (IL6) can predict PTL in asymptomatic women with $43 \%$ sensitivity, and $74 \%$ specificity [15].

In addition, Abdelazim et al. concluded that IL6 in the CVF is a sensitive marker for subclinical chorioamnionitis associated with the process of PTL [16]. In order to institute specific therapy more appropriately, it is important to have an accurate and reliable biomarker predictive test(s) to predict women at risk of PTL than currently available tests [9]. Actim Partus is a bedside immuno-enzymatic test relying on the monoclonal antibodies specific for phIGFBP1 [17]. PremaQuick is a new bed side immuno-enzymatic test replying on the monoclonal antibodies against 3 biomarkers: Native IGFBP-1, total IGFBP-1 and IL6. So, this comparative study was designed to compare the diagnostic accuracy of PremaQuick versus Actim-Partus in prediction of PTL in symptomatic women within 14 days.

\section{Patients and Methods}

Two-hundred and twenty women (220) were included in this comparative prospective study, which was conducted in the Obstetrics and Gynecology departments of Ahmadi and Dar Al-Shifa hospitals, Kuwait from March till October 2017, after approval of the study by the ethical committee of both hospitals. The studied women included in this study after informed consent, and classified into two groups; 110 women with threatened preterm labor (TPTL) in the study group and 110 controls (no TPTL). Pregnant women with singleton pregnancy, intact membranes, between $24-36$ weeks $^{+6}$, presented with regular uterine contractions lasting at least 30 seconds and occurring at least four times per $30 \mathrm{mi}-$ nutes, with significant cervical changes on digital examination (cervical dilatation $<3 \mathrm{~cm}$, cervical effacement $\leq 50 \%$ ) were included in the study group [3] [5].

Women admitted to the hospital without symptoms of PTL before 37 weeks' for fetal monitoring due to intrauterine growth retardation (IUGR) or control of diabetes or hypertension with pregnancy were included as controls.

IUGR defined when the fetal weight below the $10^{\text {th }}$ percentile for gestational age, and diagnosed by trans-abdominal ultrasound (TAS) [18]. Scifres et al., found that oligohydramnios (amniotic fluid index $<5$ ), and abnormal umbilical artery Doppler (absent or reverse end-diastolic flow) are the best predictive value for perinatal mortality in cases of IUGR [19].

Pregnant women $>37$ weeks, multiple pregnancies, cervical dilatation $\geq 3 \mathrm{~cm}$, rupture of membranes (ROM), congenital fetal malformations (CFM) or intra uterine fetal death (IUFD), cervical cerclage in place, ante-partum hemorrhage excluded from this study.

Women included in the study were subjected to; through history including the last menstrual period (LMP) to calculate accurately the gestational age, and TAS. The gestational age calculated accurately from the LMP, and early scan done before 20 weeks'. 
Abdominal examination done for the studied women to detect; the fundal level, fetal heart rate and frequency of the uterine contractions, followed by laboratory investigation according to the hospital protocols. Studied women examined in Lithotomy position with proper illumination using sterile speculum examination (no lubricants or antiseptics) for collections of the samples for PremaQuick and Actim-Partus, before TVCL assessment and digital vaginal examination.

First swab sterile Copan flocked swab (PremaQuick, Biosynex, France) provided with the kit inserted in the posterior vaginal fornix for 15 seconds to absorb the CVF. The swab placed and rotated in the buffer extraction solution provided by the manufacture for 10 seconds. Three drops from the buffer extraction solution added in each well $(S)$ of the test cassette, then the result of the test detected after 10 minutes, and recorded in the patients' chart (Figure 1). While the presence of 3 control (C) lines is necessary for validation; score 0 or score $\leq 1=$ negative test (Figure 2 ), if score $\geq 2$ = positive test (Figure 3 ).

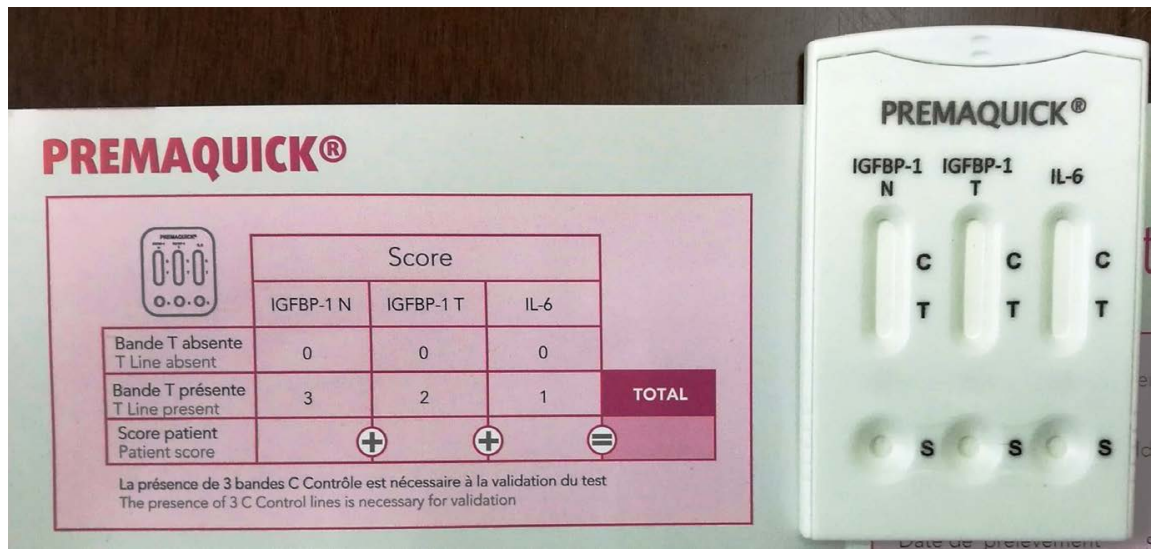

Figure 1. PremaQuick cassette and the patients' chart to detect the score of the PremaQuick test.

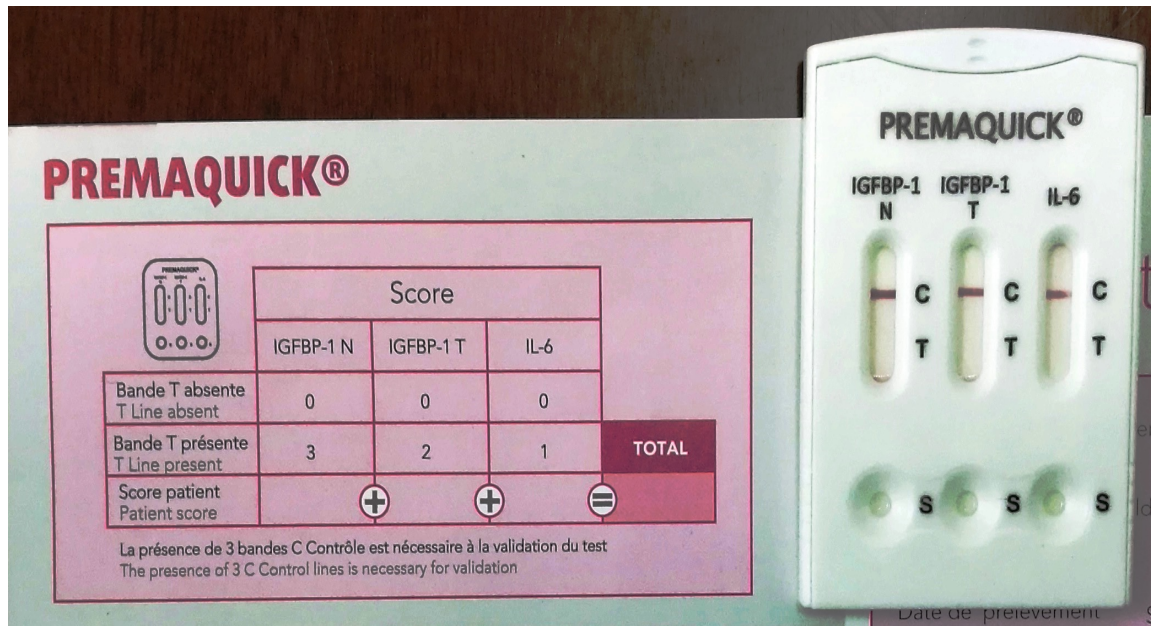

Figure 2. Triple negative PremaQuick test (Score 0; absent T line of the three biomarkers; IGFBP-1N, IBFBP-1T, and TL6). 


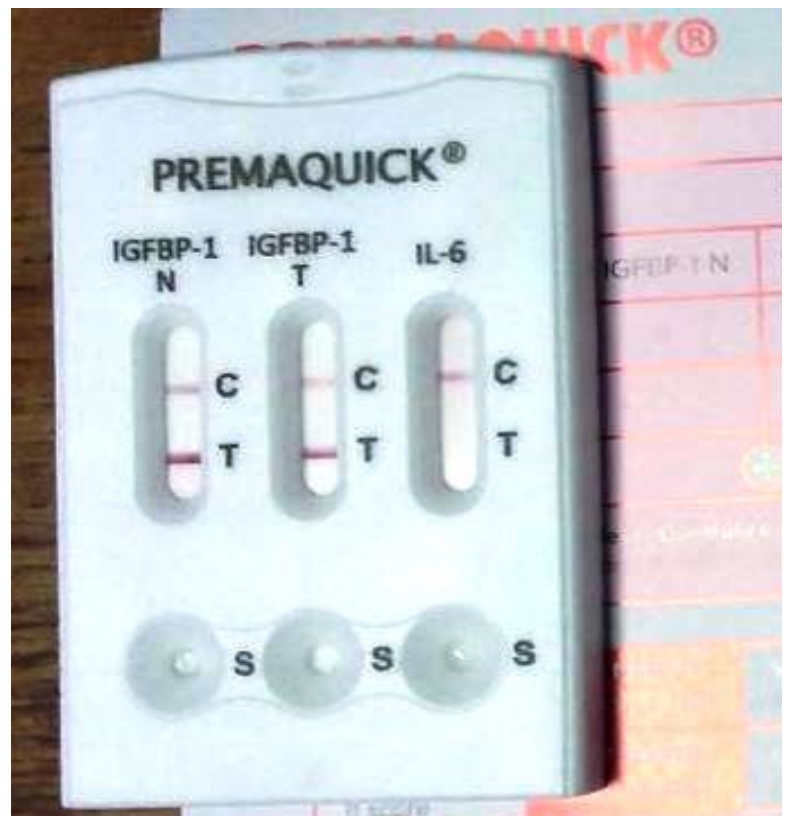

Figure 3. Positive PremaQuick test (Score 5; positive T lines of two biomarkers; IGFBP-1N, and IGFBP-1T).

PremaQuick is a new bed side immuno-enzymatic test replying on the monoclonal antibodies against 3 biomarkers; Native IGFBP-1 (Placental Protein-12 (PP12) or Placental Alpha Microglobulin-1 (PAMG-1)), total IGFBP-1 (Native + $\mathrm{N}$ terminal fragment of IGFBP-1), and interleukin-6 (IL6).

PremaQuick takes into account the major pathogenic mechanisms responsible for PTL, which offers the possibility to have high PPVs and NPVs in prediction of PTL within 14 days.

A second sterile polyester swab (Actim Partus, Medix Biochemica, Finland) inserted in the posterior vaginal fornix for 10 - 15 seconds, to absorb the CVF. The polyester swab placed, and rotated in the specimen extraction solution provided by the manufacture for 10 seconds. After extraction, the yellow area of the dipstick inserted into the extraction solution until the extraction solution reached the result area of the dipstick. Then the dipstick removed from the solution, and placed it in a horizontal position to detect the results. Positive Actim Partus test means two blue lines (control, and test lines) appear in the result area, suggesting a concentration of IGFBP-1 in the cervical secretions higher than $10 \mathrm{mg} / \mathrm{l}$. Negative Actim Partus means only the control line appear in the result area after 5 minutes.

Immediately after the sampling, the TVCL assessment was performed by an expert sonographer, blinded to the patients' clinical data, using Philips HD9 with 2D convex probe 4 - $9 \mathrm{MHz}$ (Philips international; Amsterdam; Netherlands), and standard protocol (empty bladder, minimal pressure, measurement of the maximum length between the internal and external os, before and after Valsalva manoeuvre) [20].

The measurement of the CL was accurate when the following criteria fulfilled; 
1) Sagittal plane of the cervix that allows imaging the entire length of the cervical canal. 2) Placement of the cervical plane in the middle of the ultrasound screen as horizontal as possible. 3) Absence of excess pressure on the ultrasound probe, cursors placed in precise contact with the closing points of the internal, and external cervical os. Digital vaginal examination of the studied women done to assess; the position, and the consistency of the cervix, cervical effacement, conditions of the membranes, and cervical dilatation.

Studied women admitted and managed according to the hospitals protocol regarding; administration of corticosteroids, tocolysis and bed rest, depending on the results of the PremaQuick, Actim Partus, TVCL and the clinical findings. Follow-up of the studied women was done weekly in the obstetrics outpatients' clinic after discharge from the hospital until delivery. The main outcome measures the diagnostic accuracy of PremaQuick versus Actim Partus in prediction of PTL in symptomatic women within 14 days of admission.

Sample size: The required sample size was calculated using G Power software version 3.17 for sample size calculation (Heinrich Heine Universität; Düsseldorf; Germany), setting $\alpha$-error probability at 0.05 , power (1- $\beta$ error probability) at $0.95 \%$ and effective sample size $(\mathrm{w})$ at 0.3 . The effective sample includes more than 220 women in two groups (110 in the study group, and 110 controls) needed to produce a statistically acceptable figure.

\section{Statistical Analysis}

Collected data were statistically analyzed using Statistical Package for Social Sciences (SPSS): computer software version 20 (Chicago, IL, USA). Numerical variables were presented as mean and standard deviation $( \pm \mathrm{SD})$, while categorical variables were presented as number (n) and percentage (\%). Chi-square test $\left(\mathrm{x}^{2}\right)$ was used for comparison between groups as regard qualitative variables; student $(\mathrm{t})$ test was used for comparison between groups as regard numerical variables. The Odds ratio and the relative risk of the PremaQuick, Actim Partus, and TVCL for prediction of PTL in symptomatic within 14 days were calculated. $P$-value $<0.05$ was considered statistically significant.

\section{Results}

Two-hundred and twenty women (220) were included in this comparative prospective study and classified into two groups; 110 women with TPTL in the study group and 110 controls (no TPTL). There was no significant difference between the two studied groups regarding; the mean age, and mean gestational age (Table 1).

One hundred and six $(96.4 \%(106 / 110))$ women in the study group (TPTL) delivered with 14 days, while 4 women delivered after 14 days $(3.6 \%(4 / 110)$ added to the controls). One hundred and eight women in the controls not delivered within 14 days $(98.2 \%(108 / 110))$, while two women delivered within 14 days $(1.8 \%(2 / 10)$ added to the study group). Finally 108 women in the study 
group (106 +2 from the controls), and 112 in the controls $(108+4$ from the study group) were statistically analyzed (Figure 4 ).

The cervical length (CL) $<25 \mathrm{~mm}$ was true positive (TP) in 59 women $(54.6 \%$ = sensitivity) and was false negative (FN) in 49 women (45.5\%) of the study group, while in the controls it was true negative (TN) in 63 women $(56.3 \%=$ specificity) and false positive (FP) in 49 women (43.7\%).

The PremaQuick was TP in 43 women (39.8\% sensitivity) and was FN in 65 women $(60.2 \%)$ of the study group, while in the controls it was TN in 107 women $(95.5 \%=$ specificity) and FP in 5 women $(4.5 \%)$.

The Actim Partus was TP in 15 women $(13.9 \%$ = sensitivity $)$ and was FN in 93 women $(86.1 \%)$ of the study group, while in the controls it was TN in 101 women $(90.2 \%=$ specificity) and FP in 11 women $(9.8 \%)$ (Table 2$)$.

The sensitivity and the specificity of the $\mathrm{CL}<25 \mathrm{~mm}$ to predict PTL in symptomatic women within 14 days were $54.6 \%$ and $56.3 \%$; respectively compared with 39.8\% and 95.5\%; respectively for PremaQuick, and $13.9 \%$ and $90.2 \%$; respectively for Actim Partus.

The PPV, NPV, and the accuracy of CL $<25 \mathrm{~mm}$ to predict PTL within 14 days were $54.6 \%, 56.3 \%$, and $55.5 \%$; respectively; compared with $89.6 \%, 62.2 \%$, and 68.2\%; respectively for PremaQuick, and 55.5\%, 52.1\%, and 52.7\%; respectively for Actim Partus (Table 3).

PremaQuick triple positive test detected in $44.2 \%$ (19/43) of the studied women with true positive PremaQuick results; 18 of them were TP (delivered with 14 days), and 1 was FP (not delivered within 14 days). The PPV of the triple positive PremaQuick test was $94.8 \%$ (18/19).

The PremaQuick triple negative test detected in 66.4\% (71/107) of the controls with true negative PremaQuick results; 69 of them were TN (not delivered within 14 days), and 2 were FN (delivered within 14 days). The NPV of the triple negative PremaQuick was 97.2\% (69/71).

PremaQuick test was significantly more specific with higher positive predictive value (PPV) in prediction of PTL in symptomatic women within 14 days (95.5\% and $89.6 \%$; respectively) compared to CL $<25 \mathrm{~mm}$ (56.3\% and $54.6 \%$; respectively), ( $P=0.02$ and 0.03 ; respectively).

In addition; there was no significant difference between PremaQuick and the $\mathrm{CL}<25 \mathrm{~mm}$ sensitivity, negative predictive value (NPV) and accuracy in prediction of PTL within 14 days (Table 4).

The PremaQuick test was significantly more sensitive with higher positive predictive value (PPV) in prediction of PTL in symptomatic women within 14 days (39.8\% and 89.6\%; respectively) compared to Actim Partus (13.9\% and $55.5 \%$; respectively), ( $P=0.001$, and 0.01 ; respectively).

In addition; the PremaQuick had higher specificity, negative predictive value (NPV), and accuracy (95.5\%, 62.2\% and 68.2\%; respectively) compared to Actim Partus (90.2\%, 52.1\% and 52.7\%; respectively) in prediction of PTL within 14 days (but this difference was not significant) (Table 5). 
The Odds ratio and the relative risk for prediction of PTL in symptomatic within 14 days were significantly high for PremaQuick (14.2 (95\%CI; 6.3 - 37.6) $P=0.0001$ and 8.9 (95\%CI; $3.6-21.7) P=0.0001$; respectively) compared to the $\mathrm{CL}<25 \mathrm{~mm}(1.5$ (95\%CI; $0.9-2.6) P=0.1$ and 1.2 (95\%CI; $0.9-1.6) P=0.1$; respectively), and Actim Partus (1.4 (95\%CI; 0.6 - 3.3) $P=0.3$ and 1.4 (95\%CI; 0.7 - 2.9); $P=0.3$ respectively) (Table 6 ).

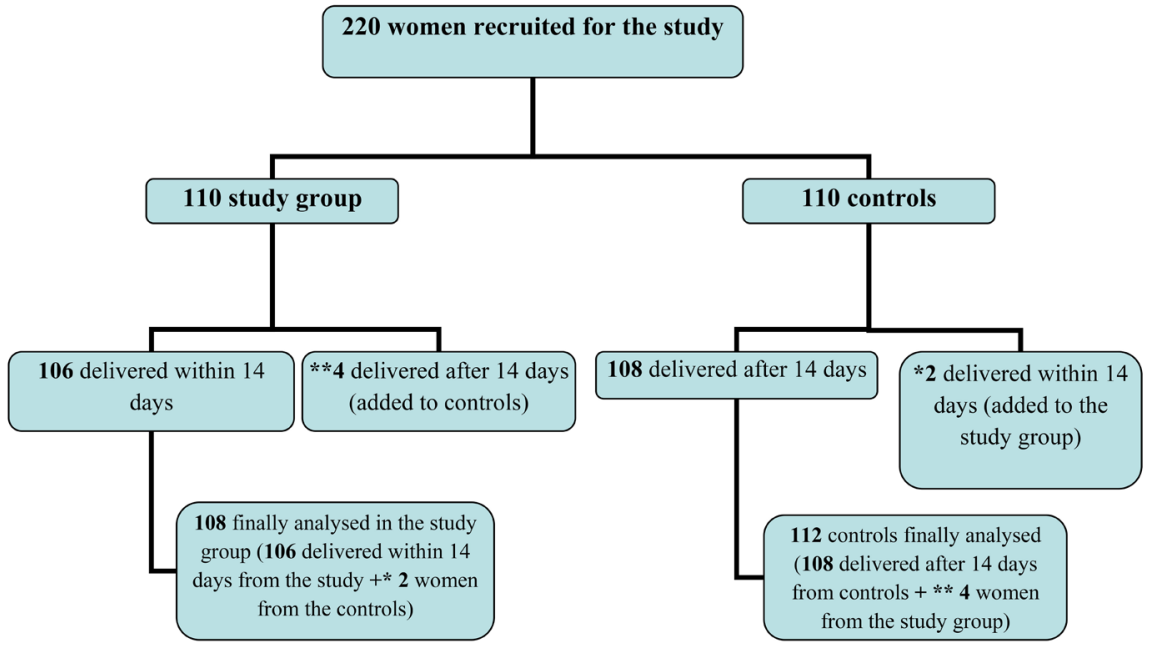

Figure 4. The study flow chart. 108 women finally analysed in the study group (106 delivered within 14 days from the study $+{ }^{\star} 2$ women from the controls). 112 controls finally analyzed (108 women delivered after 14 days from controls $+{ }^{* *} 4$ women from the study group).

Table 1. The maternal age and the gestational age for the studied women.

\begin{tabular}{cccc}
\hline Variables & $\begin{array}{c}\text { Study Group (TPTL) } \\
\text { (Sample size }=110 \\
\text { Women) }\end{array}$ & $\begin{array}{c}\text { Control Group } \\
\text { (Sample size } 110 \\
\text { Women) }\end{array}$ & $\begin{array}{c}\text { T test } P \text { Value } \\
\text { (95\% Confidence Interval) }\end{array}$ \\
\hline $\begin{array}{c}\text { Maternal age (years) } \\
\text { Mean } \pm \text { SD } \\
\begin{array}{c}\text { Gestational age } \\
\text { (weeks) Mean } \pm \text { SD }\end{array}\end{array}$ & $31.5 \pm 4.8$ & $29.3 \pm 5.6$ & $0.94^{*}(0.82,2.2,3.6)$ \\
\hline
\end{tabular}

${ }^{\star}$ Non-Significant difference. Data presented as mean \pm standard deviation (SD). TPTL: Threatened preterm labor.

Table 2. The results of the cervical length $<25 \mathrm{~mm}$, PremaQuick, Actim Partus in the two studied groups.

\begin{tabular}{|c|c|c|c|c|}
\hline \multirow[b]{2}{*}{ Variables } & \multicolumn{2}{|c|}{$\begin{array}{c}\text { Study Group (TPTL) } \\
\text { (Sample size } 108 \text { Women) }\end{array}$} & \multicolumn{2}{|c|}{$\begin{array}{c}\text { Control Group } \\
\text { (Sample size } 112 \text { Women) }\end{array}$} \\
\hline & $\begin{array}{l}\text { Positive cases } \\
\text { True Positive } \\
\text { Number (\%) }\end{array}$ & $\begin{array}{c}\text { Negative cases } \\
\text { False Negative } \\
\text { Number (\%) }\end{array}$ & $\begin{array}{l}\text { Positive cases } \\
\text { False Positive } \\
\text { Number (\%) }\end{array}$ & $\begin{array}{c}\text { Negative cases } \\
\text { True Negative } \\
\text { Number (\%) }\end{array}$ \\
\hline Cervical length $<25 \mathrm{~mm}$ & $59 / 108$ & $15.4 \%)$ & $49 / 112(43.7 \%)$ & $63 / 112(56.3 \%)$ \\
\hline PremaQuick test & $43 / 108(39.8 \%)$ & $65 / 108(60.2 \%)$ & $5 / 112(4.5 \%)$ & $107 / 112(95.5 \%)$ \\
\hline Actim Partus test & 15/108 (13.9\%) & $93 / 108(86.1 \%)$ & $11 / 112(9.8 \%)$ & $101 / 112(90.2 \%)$ \\
\hline
\end{tabular}

Data presented as Number and percentage (\%). TPTL: Threatened preterm labor. 
Table 3. The Accuracy of the cervical length $<25 \mathrm{~mm}$, PremaQuick and Actim Partus in prediction of PTL within 14 days.

\begin{tabular}{|c|c|c|c|}
\hline Variables & $\begin{array}{c}\text { Cervical Length }<25 \\
\mathrm{~mm}\end{array}$ & PremaQuick & Actim Partus \\
\hline Sensitivity $=\mathrm{TP} /(\mathrm{TP}+\mathrm{FN})$ & $59 /(59+49) \times 100$ & $43 /(43+65) \times 100$ & $15 /(15+93) \times 100$ \\
\hline$\times 100$ & $=54.6 \%$ & $=39.8 \%$ & $=13.9 \% \%$ \\
\hline Specificity $=\mathrm{TN} /(\mathrm{TN}+\mathrm{FP})$ & $63 /(63+49) \times 100$ & $107 /(107+5) \times 100$ & $101 /(101+11) \times 100$ \\
\hline$\times 100$ & $=56.3 \%$ & $=95.5 \%$ & $=90.2 \%$ \\
\hline $\mathrm{PPV}=\mathrm{TP} /(\mathrm{TP}+\mathrm{FP}) \times 100$ & $\begin{array}{c}59 /(59+49) \times 100 \\
=54.6 \%\end{array}$ & $\begin{array}{c}43 /(43+5) \times 100 \\
\quad=89.6 \%\end{array}$ & $\begin{array}{c}15 /(15+11) \times 100 \\
=55.5 \%\end{array}$ \\
\hline $\begin{array}{c}\mathrm{NPV}=\mathrm{TN} /(\mathrm{TN}+\mathrm{FN}) \times \\
100\end{array}$ & $\begin{array}{c}63 /(63+49) \times 100 \\
=56.3 \%\end{array}$ & $\begin{array}{c}107 /(107+65) \times 100 \\
=62.2 \%\end{array}$ & $\begin{array}{c}101 /(101+93) \times 100 \\
=52.1 \%\end{array}$ \\
\hline $\begin{array}{c}\text { Accuracy }=\mathrm{TP}+\mathrm{TN} /(\mathrm{TP}+ \\
\mathrm{TN}+\mathrm{FP}+\mathrm{FN}) \times 100\end{array}$ & $\begin{array}{c}59+63 /(59+63+49 \\
+49) \times 100=55.5 \%\end{array}$ & $\begin{array}{c}43+107 /(43+107+5+ \\
65) \times 100=68.2 \%\end{array}$ & $\begin{array}{l}15+101 /(15+101+11 \\
+93) \times 100=52.7 \%\end{array}$ \\
\hline
\end{tabular}

Data presented as Number and percentage (\%). FN: False negative. FP: False positive. NPV: Negative predictive value. PPV: Positive predictive value. PTL: Preterm labor. TN: True negative. TP: True positive.

Table 4. The Accuracy of the PremaQuick compared to cervical length $<25 \mathrm{~mm}$ in prediction of PTL within 14 days.

\begin{tabular}{cccc}
\hline Variables & Cervical Length $<25 \mathrm{~mm}$ & PremaQuick & Pvalue \\
\hline Sensitivity & $59 /(59+49) \times 100=54.6 \%$ & $43 /(43+65) \times 100=39.8 \%$ & 0.15 \\
Specificity & $63 /(63+49) \times 100=56.3 \%$ & $107 /(107+5) \times 100=95.5 \%$ & $0.02^{*}$ \\
PPV & $59 /(59+49) \times 100=54.6 \%$ & $43 /(43+5) \times 100=89.6 \%$ & $0.03^{*}$ \\
NPV & $63 /(63+49) \times 100=56.3 \%$ & $107 /(107+65) \times 100=62.2 \%$ & 0.7 \\
& $59+63 /(59+63+49+49) \times 100$ & $43+107 /(43+107+5+65) \times 100$ & \\
Accuracy & $=55.5 \%$ & $=68.2 \%$ & 0.4 \\
\end{tabular}

${ }^{*}$ Significant difference. Chi-square test $\left(\mathrm{x}^{2}\right)$ used for statistical analysis. Data presented as Number and percentage (\%). NPV: Negative predictive value. PPV: Positive predictive value. PTL: Preterm labor.

Table 5. The Accuracy of the PremaQuick compared to Actim-Partus in prediction of PTL within 14 days.

\begin{tabular}{cccc}
\hline Variables & PremaQuick & Actim Partus & $P$ value \\
\hline Sensitivity & $43 /(43+65) \times 100=39.8 \%$ & $15 /(15+93) \times 100=13.9 \%$ & $0.001^{*}$ \\
Specificity & $107 /(107+5) \times 100=95.5 \%$ & $101 /(101+11) \times 100=90.2 \%$ & 0.6 \\
PPV & $43 /(43+5) \times 100=89.6 \%$ & $15 /(15+11) \times 100=55.5 \%$ & $0.01^{*}$ \\
NPV & $107 /(107+65) \times 100=62.2 \%$ & $101 /(101+93) \times 100=52.1 \%$ & 0.3 \\
& $43+107 /(43+107+5+65) \times 100=$ & $15+101 /(15+101+11+93) \times 100=$ & 0.1 \\
Accuracy & $68.2 \%$ & $52.7 \%$ & \\
\hline
\end{tabular}

${ }^{*}$ Significant difference. Chi-square test $\left(\mathrm{x}^{2}\right)$ used for statistical analysis. Data presented as Number and percentage (\%). NPV: Negative predictive value. PPV: Positive predictive value. PTL: Preterm labor. 
Table 6. The Odds ratio and the relative risk of the PremaQuick, $\mathrm{CL}<25 \mathrm{~mm}$ and Actim-Partus in prediction of PTL within 14 days.

\begin{tabular}{cccc}
\hline Variables & $\begin{array}{c}\text { Positive } \\
\text { outcome }\end{array}$ & $\begin{array}{c}\text { Negative } \\
\text { outcome }\end{array}$ & $\begin{array}{c}\text { Odds ratio (95\% CI) } P \text { value } \\
\text { RR }(95 \% \text { CI }) P \text { value }\end{array}$ \\
\hline $\begin{array}{c}\text { PremaQuick } \\
\text { Study group }\end{array}$ & 43 & 65 & $14.2(6.3-37.6) 0.0001^{*}$ \\
Control group & 5 & 107 & $8.9(3.6-21.7) 0.0001^{*}$ \\
Cervical length $<25 \mathrm{~mm}$ & 59 & & $1.5(0.9-2.6) 0.1$ \\
Study group & 49 & 69 & $1.2(0.9-1.6) 0.1$ \\
Control group & & & $1.4(0.6-3.3) 0.3$ \\
Actim-Partus & 15 & 93 & $1.4(0.7-2.9) 0.3$ \\
Study group & 11 & 101 & \\
Control group & & & \\
\hline
\end{tabular}

${ }^{\star}$ Significant difference. $\mathrm{CI}=$ Confidence interval. $\mathrm{PTL}=$ Preterm labor. $\mathrm{RR}=$ Relative Risk.

\section{Discussion}

PTL is a major cause of neonatal morbidity and mortality [1] [2]. TVCL and/or cervico-vaginal fFN are the most common diagnostic tools used for prediction of PTL [7]. Both methods have high NPVs with low PPVs. Consequently; many women and their fetuses are exposed to unnecessarily tocolysis, corticosteroid and hospital admission.

TVCL at $25 \mathrm{~mm}$ threshold has limited sensitivity (78.3\%), and specificity (71\%) in detection of PTL [8]. fFN has poor PPV for detection of PTL, and used mainly in detection of PTL due to its high NPV [10] [11]. IGFBP-1 belongs to the insulin like binding proteins super-family secreted from the decidua, released into CVF during the process of the chorio-decidual disruption and its detection in the CVF associated with increased risk of PTL [12] [13]. Clinical diagnostic trials indicate that fFN and phIGFBP1 are good negative predictors of PTL (92\% specificity) with limited sensitivity, and PPVs in asymptomatic women [14].

Taylor et al., concluded that the IL6 can predict PTL in asymptomatic women with $43 \%$ sensitivity, and $74 \%$ specificity [15]. Abdelazim et al., concluded that IL6 in the CVF is a sensitive marker associated with the process of PTL [16]. Kurkinen-Räty et al., concluded that the CVF IL6 increases in PTL, and the cervical phIGFBP1 seems to be a good marker of degradation at the chorio-decidual interface associated with PTL [21].

Hadži-Lega et al., suggested that IL6 at a cut-off of $1305 \mathrm{pg} / \mathrm{ml}$ correctly identifies women that will deliver within 14 days from admission with $69.4 \%$ sensitivity, 68.2\% specificity, 78.1\% PPV, 57.69\% NPV [22].

Woodworth et al., studied the diagnostic utility of fFN and IL6 in CVF to predict PTL within 14 days of sampling in African-American, and Caucasian women. They concluded that the CVF IL6 and fFN have similar diagnostic utilities in a diverse population [23].

In order to institute specific therapy more appropriately, it is important to 
have an accurate and reliable biomarker predictive test(s) to predict women at risk of PTL than currently available tests [9]. Actim-Partus is a bedside immuno-enzymatic test relying on the monoclonal antibodies specific for phIGFBP1 [17]. PremaQuick is a new bed side immuno-enzymatic test replying on the monoclonal antibodies against 3 biomarkers (Native IGFBP-1, total IGFBP-1, and IL-6). So, this comparative study was designed to compare the diagnostic accuracy of PremaQuick versus Actim Partus in detection of PTL in symptomatic women within 14 days.

In this study; the sensitivity and the specificity of the $\mathrm{CL}<25 \mathrm{~mm}$ to predict PTL in symptomatic women within 14 days were $54.6 \%$ and $56.3 \%$; respectively compared with $39.8 \%$ and $95.5 \%$; respectively for PremaQuick, and $13.9 \%$, and 90.2\%; respectively for Actim Partus.

The PPV, NPV and the accuracy of CL $<25 \mathrm{~mm}$ to predict PTL within 14 days were 54.6\%, 56.3\% and 55.5\%; respectively; compared with $89.6 \%, 62.2 \%$ and 68.2\%; respectively for PremaQuick, and 55.5\%, 52.1\% and 52.7\%; respectively for Actim Partus.

Rahkonen et al. found that the CVF phIGFBP-1 level of $\geq 10 \mathrm{ug} / \mathrm{l}$ predicts PTL with sensitivities varying from $40.0 \%$ to $89.5 \%$ and NPVs from $90 \%$ to $100 \%$ [24]. Rahkonen et al. concluded that the elevated phIGFBP1 level in the first trimester was an independent predictor of spontaneous PTL, especially $<32$ gestational weeks [24].

Although Gramellini et al. concluded that the NPV for delivery within 7 days exceeded $90 \%$ when the CL was $>25 \mathrm{~mm}$ [25] and Boudhraa et al. found that the $\mathrm{CL} \leq 25 \mathrm{~mm}$ had $100 \%$ sensitivity, 59\% specificity, 100\% NPV, and $28 \%$ PPV [26]. The PremaQuick test in this study was significantly more specific, with higher PPV in prediction of PTL in symptomatic women within 14 days compared to the $\mathrm{CL}<25 \mathrm{~mm}$ ( $P=0.02$, and 0.03 ; respectively).

Also, Sotiriadis et al. concluded that the commonly used TVCL for prediction of PTL had limited sensitivity (78.3\%), and specificity (71\%) at $25 \mathrm{~mm}$ threshold [8]. In addition, Schmitz et al. concluded that the sensitivity, specificity, and PPVs of CL $\leq 25 \mathrm{~mm}$ were $75 \%, 63 \%, 24 \%$ and $94 \%$, respectively [27].

The PremaQuick test in this study was significantly more sensitive with higher PPV in prediction of PTL in symptomatic women within 14 days compared to Actim Partus ( $P=0.001$ and 0.01 ; respectively). In addition; the PremaQuick had higher specificity, NPV and accuracy compared to Actim Partus in prediction of PTL within 14 days (but this difference was not significant).

The diagnostic accuracy of Actim Partus in asymptomatic woman at risk of PTL evaluated by Khambay et al., and they found that the predictive values of the Actim Partus for delivery at $\leq 37$ weeks' gestation were $0 \%$ and $70 \%$, respectively [28]. Khambay et al. concluded that the Actim Partus test did not perform well as a predictor of PTL [28].

The PremaQuick test in this study was significantly more specific with higher PPV in prediction of PTL in symptomatic women within 14 days compared to 
$\mathrm{CL}<25 \mathrm{~mm}(P=0.02$, and 0.03; respectively). When the PremaQuick test results combine to the $\mathrm{CL}<25$, it compensates the low specificity and low PPV of the CL in prediction of PTL.

In addition; the PremaQuick triple positive test has a unique high PPV of 94.8\% (18/19), and the triple negative test has a characteristic high NPV of 97.2\% (69/71) in detection of PTL in symptomatic women within 14 days.

The Odds ratio and the relative risk for prediction of PTL in symptomatic women within 14 days were significantly high for PremaQuick compared to the $\mathrm{CL}<25 \mathrm{~mm}$, and Actim Partus.

Eroglu et al. concluded that when the results of fFN/phIGFBP-1 test and CL < $25 \mathrm{~mm}$ were combined, the specificity, and the PPVs values of each test for delivery within 7 days increased [29].

Rahkonen et al. in another study reported that the CVF phIGFBP-1 could play a role either alone or in combination with other markers and/or risk factors when assessing the risk for PT, planning prenatal care, and interventions in selected women [30].

The results of this study suggest that the PremaQuick test is the best complementary test to the $\mathrm{CL}<25$ in prediction of PTL in symptomatic women within 14 days. The PremaQuick test compensates the low specificity and low PPV of the $\mathrm{CL}<25 \mathrm{~mm}$ in prediction of PTL in symptomatic women.

The strength of this study is coming from being the first study done to compare the diagnostic accuracy of PremaQuick versus Actim Partus in prediction of PTL in symptomatic women within 14 days.

Little available studies for the PremaQuick, and Actim Partus bed side tests in prediction of PTL was the only limitation faced during conduction of this study. Future comparative study needed to confirm that the PremaQuick is the best complementary test to increase the diagnostic accuracy (especially the specificity and the PPV) of the cervical length in prediction of PTL.

\section{Conclusion}

PremaQuick test seems to be the best complementary test to the CL $<25$ in prediction of PTL in symptomatic women within 14 days. PremaQuick test compensates the low specificity and low PPV of the CL $<25 \mathrm{~mm}$ in prediction of PTL.

\section{Disclaimer}

Biosynex SA, France supplied the PremaQuick kits, and not involved in any part of this study or analysis of the data.

\section{Acknowledgements}

Authors appreciate the effort done by Doctor Thierry Paper, President of Biosynex SA, for his continuous support, and supply of the PremaQuick kits used during this study. 


\section{Authors' Contribution}

Ibrahim A. Abdelazim is responsible for study design, statistical analysis, and submission for publication.

Mohannad Abu-Faza is responsible for collection of samples, and data for statistical analysis.

Shikanova Svetlana is responsible for intellectual content, and update of references.

Bassam Nusair is responsible for word processing, and final revision before publication.

Rania H. Farag is responsible for collection of samples, and data for statistical analysis.

Sreelatha R. Nair is responsible for collection of samples and final revision before publication.

\section{Conflicts of Interest}

Authors declared no conflict of interest related to this article.

\section{References}

[1] Alexander, G.R., Kogan, M., Bader, D., Carlo, W., Allen, M. and Mor, J. (2003) US Birth Weight/Gestational Age-Specific Neonatal Mortality: 1995-1997 Rates for Whites, Hispanics, and Blacks. Pediatrics, 111, e61-e66. https://doi.org/10.1542/peds.111.1.e61

[2] Martin, J.A., Kung, H.C., Mathews, T.J., Hoyert, D.L., Strobino, D.M., Guyer, B. and Sutton, S.R. (2008) Annual Summary of Vital Statistics: 2006. Pediatrics, 121, 788-801. https://doi.org/10.1542/peds.2007-3753

[3] Goffinet, F. and Kayem G. (2002) Diagnosis and Prognosis of Preterm Labor: Physical Examination and Ultrasonography. Journal de Gynécologie Obstétrique et Biologie de la Reproduction (Paris), 31, 5S22-5S34. (Article in French)

[4] Goldenberg, R.L., Iams, J.D., Mercer, B.M., Meis, P., Moawad, A., Das, A., Copper, R. and Johnson, F. (2003) National Institute of Child Health and Human Development Maternal-Fetal Medicine Units Network. What We Have Learned about the Predictors of Preterm Birth. Seminars in Perinatology, 27, 185-193. https://doi.org/10.1016/S0146-0005(03)00017-X

[5] Romero, R., Mazor, M., Munoz, H., Gomez, R., Galasso, M. and Sherer, D.M. (1994) The Preterm Labor Syndrome. Annals of the New York Academy of Sciences, 734, 414-429. https://doi.org/10.1111/j.1749-6632.1994.tb21771.x

[6] Lockwood, C.J. and Kuczynski, E. (2001) Risk Stratification and Pathological Mechanisms in Preterm Delivery. Paediatric and Perinatal Epidemiology, 15, 78-89. https://doi.org/10.1046/j.1365-3016.2001.00010.x

[7] Gomez, R., Romero, R., Medina, L., Nien, J.K., Chaiworapongsa, T., Carstens, M., et al. (2005) Cervicovaginal Fibronectin Improves the Prediction of Preterm Delivery Based on Sonographic Cervical Length in Patients with Preterm Uterine Contractions and Intact Membranes. American Journal of Obstetrics and Gynecology, 192 350-359. https://doi.org/10.1016/j.ajog.2004.09.034

[8] Sotiriadis, A., Papatheodorou, S., Kavvadias, A. and Makrydimas, G. (2010) Transvaginal Cervical Length Measurement for Prediction of Preterm Birth in Women 
with Threatened Preterm Labor: A Meta-Analysis. Ultrasound in Obstetrics \& Gynecology, 35, 54-64. https://doi.org/10.1002/uog.7457

[9] Georgiou, H.M., Di Quinzio, M.K.W., Permezel, M. and Brennecke, S.P. (2015) Predicting Preterm Labour: Current Status and Future Prospects. Disease Markers, 2015, Article ID: 435014. https://doi.org/10.1155/2015/435014

[10] Compan, C., Rossi, A., Piquier-Perret, G., Delabaere, A., Vendittelli, F., Lemery, D. and Gallot, D. (2015) Prédiction de la prématurité en cas de menace d'accouchement prématuré: Revue de la littérature. Journal de Gynécologie Obstétrique et Biologie de la Reproduction, 44, 740-775. https://doi.org/10.1016/j.jgyn.2015.06.008

[11] Leitich, H., Egarter, C., Kaider, A., Hohlagschwandtner, M., Berghammer, P. and Husslein, P. (1999) Cervicovaginal Fetal Fibronectin as a Marker for Preterm Delivery: A Meta-Analysis. American Journal of Obstetrics \& Gynecology, 180, 1169-1176. https://doi.org/10.1016/S0002-9378(99)70612-5

[12] Lembet, A., Eroglu, D., Ergin, T., Kuscu, E., Zeyneloglu, H., Batioglu, S. and Haberal, A. (2002) New Rapid Bed-Side Test to Predict Preterm Delivery: Phosphorylated Insulin-Like Growth Factor Binding Protein-1 in Cervical Secretions. Acta Obstetricia et Gynecologica Scandinavica, 81, 706-712. https://doi.org/10.1034/j.1600-0412.2002.810804.x

[13] Kekki, M., Kurki, T., Paavonen, J. and Rutanen, E.M. (1999) Insulin-Like Growth Factor Binding Protein-1 in Cervix as a Marker of Infectious Complications in Pregnant Women with Bacterial Vaginosis. Lancet, 353, 1494. https://doi.org/10.1016/S0140-6736(99)00400-6

[14] Woodworth, A., Moore, J., G’Sell, C., Verdoes, A., Snyder, J.A., Morris, L., Wares, C., Grenache, D.G. and Gronowski, A.M. (2007) Diagnostic Accuracy of Cervicovaginal Interleukin-6 and Interleukin-6: Albumin Ratio as Markers of Preterm Delivery. Clinical Chemistry, 53, 1534-1540. https://doi.org/10.1373/clinchem.2007.084798

[15] Taylor, B.D., Holzman, C.B., Fichorova, R.N., Tian, Y., Jones, N.M., Fu, W. and Senagore, P.K. (2013) Inflammation Biomarkers in Vaginal Fluid and Preterm Delivery. Human Reproduction, 28, 942-952. https://doi.org/10.1093/humrep/det019

[16] Abdelazim, I.A. (2013) Relation between Interleukin-6 in Cervicovaginal Fluid and Subclinical Chorioamnionitis in Patients with Preterm Premature Rupture of Membranes. Asian Pacific Journal of Reproduction, 2, 38-41. https://doi.org/10.1016/S2305-0500(13)60113-X

[17] Kwek, K., Khi, C., Ting, H.S. and Yeo, G.S. (2004) Evaluation of a Bedside Test for Phosphorylated Insulin-Like Growth Factor Binding Protein-1 in Preterm Labour. Annals of the Academy of Medicine of Singapore, 33, 780-783.

[18] Giuliano, N., Annunziata, M.L., Tagliaferri, S., Esposito, F.G., Imperato, O.C., Campanile, M., et al. (2014) IUGR Management: New Perspectives. Journal of Pregnancy, 2014, Article ID: 620976.

[19] Scifres, C.M., Stamilio, D., Macones, G.A. and Odibo, A.O. (2009) Predicting Perinatal Mortality in Preterm Intrauterine Growth Restriction. American Journal of Perinatology, 26, 723-728. https://doi.org/10.1055/s-0029-1223284

[20] Lim, K., Butt, K. and Crane, J.M., Diagnostic Imaging Committee, Family Physicians Advisory Committee, Maternal Fetal Medicine Committee (2011) SOGC Clinical Practice Guideline. Ultrasonographic Cervical Length Assessment in Predicting Preterm Birth in Singleton Pregnancies. Journal of Obstetrics and Gynae- 
cology Canada, 33, 486-499. https://doi.org/10.1016/S1701-2163(16)34884-8

[21] Kurkinen-Räty, M., Ruokonen, A., Vuopala, S., Koskela, M., Rutanen, E.M., Kärkkäinen, T. and Jouppila, P. (2001) Combination of Cervical Interleukin-6 and -8, Phosphorylated Insulin-Like Growth Factor-Binding Protein-1 and Transvaginal Cervical Ultrasonography in Assessment of the Risk of Preterm Birth. BJOG, 108, 875-881. https://doi.org/10.1111/j.1471-0528.2001.00199.x

[22] Hadži-Lega, M., Markova, A.D., Stefanovic, M. and Tanturovski, M. (2015) Interleukin 6 and Fetal Fibronectin as a Predictors of Preterm Delivery in Symptomatic Patients. Bosnian Journal of Basic Medical Sciences, 15, 51-56. https://doi.org/10.17305/bjbms.2015.1.93

[23] Woodworth, A., Grenache, D.G. and Gronowski, A.M. (2011) Cervicovaginal Interleukin-6 as a Predictor of Preterm Birth in African American Women. Clinica Chimica Acta, 412, 988-992. https://doi.org/10.1016/j.cca.2011.02.001

[24] Rahkonen, L., Rutanen, E.M., Nuutila, M., Sainio, S., Saisto, T. and Paavonen, J. (2010) Elevated Levels of Decidual Insulin-Like Growth Factor Binding Protein-1 in Cervical Fluid in Early and Mid-Pregnancy Are Associated with an Increased Risk of Spontaneous Preterm Delivery. BJOG, 117, 701-710. https://doi.org/10.1111/j.1471-0528.2010.02551.x

[25] Gramellini, D., Fieni, S., Kaihura, C. and Modena, A.B. (2007) Cervical Length as a Predictor of Preterm Delivery: Gestational Age-Related Percentiles vs. Fixed Cut-Offs. Acta BioMedica, 78, 220-224.

[26] Boudhraa, K., Rahouej, H. and Gara, M.F. (2008) Transvaginal Ultrasound of the Cervix in the Estimation of Severity of Premature Labour. La Tunisie Médicale, 86, 745-748.

[27] Schmitz, T., Maillard, F., Bessard-Bacquaert, S., Kayem, G., Fulla, Y., Cabrol, D. and Goffinet, F. (2006) Selective Use of Fetal Fibronectin Detection after Cervical Length Measurement to Predict Spontaneous Preterm Delivery in Women with Preterm Labor. American Journal of Obstetrics \& Gynecology, 194, 138-143. https://doi.org/10.1016/j.ajog.2005.05.074

[28] Khambay, H., Bolt, L.A., Chandiramani, M., De Greeff, A., Filmer, J.E. and Shennan, A.H. (2012) The Actim Partus Test to Predict Pre-Term Birth in Asymptomatic High-Risk Women. Journal of Obstetrics and Gynaecology, 32, 132-134. https://doi.org/10.3109/01443615.2011.637649

[29] Eroglu, D., Yanik, F., Oktem, M., Zeyneloglu, H.B. and Kuscu, E. (2007) Prediction of Preterm Delivery among Women with Threatened Preterm Labor. Gynecologic and Obstetric Investigation, 64, 109-116. https://doi.org/10.1159/000100120

[30] Rahkonen, L., Unkila-Kallio, L., Nuutila, M., Sainio, S., Saisto, T., Rutanen, E.M. and Paavonen, J. (2009) Cervical Length Measurement and Cervical Phosphorylated Insulin-Like Growth Factor Binding Protein-1 Testing in Prediction of Preterm Birth in Patients Reporting Uterine Contractions. Acta Obstetricia et Gynecologica Scandinavica, 88, 901-908. https://doi.org/10.1080/00016340903104281 